\title{
A contribuição do lúdico para melhoria do processo de ensino e aprendizagem dos alunos do Ensino Fundamental.
}

The contribution of the ludic to improveme the teaching and learning process of elementary school students.

Lenir Santos do Nascimento Moura Escola Municipal Mi-Vó, Alto Alegre, Roraima, (Brasil) lenirsantosnasc@gmail.com

Marilene Kreutz de Oliveira

Colégio Estadual Militarizado Desembargador Sadoc Pereira, Alto Alegre, Roraima, (Brasil) marilenekreutz@hotmail.com

Maria Conceição Vieira Sampaio

Colégio Estadual Militarizado Desembargador Sadoc Pereira, Alto Alegre, Roraima, (Brasil) conceicaoaltoalegre@gmail.com

Leandro Santos do Nascimento

Escola do Legislativo do Estado de Roraima, Alto Alegre, Roraima, (Brasil) jhow.leandro31@gmail.com

Fecha recepción: 12/10/2019

Páginas 1-15

Fecha aceptación: 25/11/2019

\section{Resumo.}

Esta pesquisa trata de analisar a contribuição do lúdico para melhoria no processo de ensino e aprendizagem dos alunos do $1^{\circ}$ ano do Ensino Fundamental da Escola Municipal Professora Edneide Sales Campelo, Alto Alegre/Roraima/Brasil. A investigação teve como objetivo: Verificar se as atividades lúdicas como recurso pedagógico podem desenvolver práticas mais atrativas segundo a percepção dos professores; 0 objetivo buscou responder o seguinte problema: O lúdico utilizado como recurso pedagógico contribui para melhoria do ensino e da aprendizagem dos alunos do $1^{\circ}$ ano do ensino fundamental da Escola Municipal Professora Edneide Sales Campelo? A pesquisa é do tipo não-experimental, descritiva com o enfoque qualitativo e paradigma interpretativo. Como técnica para a coleta de dados realizou-se uma entrevista. Os sujeitos participantes da pesquisa foram: os 14 (catorze) professores do $1^{\circ}$ ano do ensino fundamental da escola em estudo. Foram utilizados como instrumento uma entrevista semiestruturadas. Os resultados encontrados referentes a contribuição do lúdico para o processo de ensino segundo a opinião dos professores foram: prática inovadora, desde que sejam bem planejadas e adequadas a faixa etária dos educandos promovendo aulas atrativas, dinâmicas, divertidas, prazerosas, eficazes e significativas, possibilitando a construção da afetividade.

Palavras-chave: lúdico; ensino; aprendizagem; interação; socialização 


\begin{abstract}
.
This research aims to analyze the contribution of the ludic to improve the teaching and learning process of the students of the 1st year of Elementary School of the Municipal School Teacher Edneide Sales Campelo, Alto Alegre / Roraima / Brazil. The research aimed to: Verify whether playful activities as a pedagogical resource can develop more attractive practices according to teachers' perception; The objective was to answer the following problem: Does the playfulness used as a pedagogical resource contribute to the improvement of the teaching and learning of the students of the 1st year of elementary school at the Municipal School Teacher Edneide Sales Campelo? The research is non-experimental, descriptive with a qualitative approach and interpretative paradigm. As a technique for data collection, an interview was conducted. The subjects participating in the research were: the 14 (fourteen) teachers of the 1 st year of elementary school of the school under study. A semi-structured interview was used as instrument. The results found regarding the contribution of the ludic to the teaching process according to the teachers 'opinion were: innovative practice, provided that the students' age range are well planned and appropriate, promoting attractive, dynamic, fun, pleasant, effective and meaningful classes, enabling the construction of affectivity.
\end{abstract}

Keywords: playful; teaching; learning; interaction; socialization

\title{
1.-Introdução.
}

O presente artigo trata-se de parte da Dissertação intitulada "A contribuição do lúdico para melhoria do processo de ensino e aprendizagem dos alunos do $1^{\circ}$ ano do Ensino Fundamental da Escola Municipal Professora Edneide Sales Campêlo, Alto Alegre/Roraima/ Brasil", apresentada à Universidad Autónoma de Asunción Faculdad de Ciencias Humanísticas y de la Educación Programa de Maestria en Educación, no período de 2009 à 2012, para a obtenção do título de Mestre em Ciências da Educação.

As atividades lúdicas são de fundamental importância para a formação do ser humano tanto no aspecto educacional e fisiológico como nos campos psicológicos e sociais. Através delas o educador pode perceber no educando traços de personalidade, comportamento individual e grupal, além do seu ritmo de desenvolvimento. Com o lúdico o educando tem a possibilidade de desenvolver sua criatividade, socialização, coordenação, memorização, vocabulário, entre outros pontos que se somam de forma positiva e satisfatória em benefício da aprendizagem. Para que ocorra o desenvolvimento de tais potencialidades o educador deverá propiciar ao educando um ambiente aconchegante, desafiador, rico em oportunidades e esteja pronto para a exploração da curiosidade, assim como ao incentivo do desenvolvimento da criatividade, das diferentes formas de linguagem, do senso crítico e de progressiva autonomia.

São diversos os pontos que devem ser observados na aplicação do lúdico em sala de aula, esta prática deve ser pensada desde o início começando pelo plano pedagógico da escola criando condições para um desenvolvimento mais rico e proveitoso. A escola deverá disponibilizar dos recursos necessários para o bom desenvolvimento da prática pedagógica, com um ambiente adequado, materiais didáticos e pedagógicos, recursos humanos capacitados para trabalhar com alunos, em fim criar todo um universo de condições para facilitar a inserção do aluno e a criação de novos conhecimentos para o desenvolvimento de habilidade e competências. 
0 presente estudo tem a finalidade de verificar se as atividades lúdicas como recurso pedagógico podem desenvolver práticas mais atrativas segundo a percepção dos professores;

\section{2.-Infância, lúdico e brincar.}

A infância de uma criança é um dos períodos mais significantes para sua vida, pois é neste período que ela tem suas primeiras experiências e passa a explorar o mundo que à cerca com mais intensidade.

Neste período da vida as etapas vividas e compostas por suas singularidades impares são marcantes. Desta forma, podemos dizer que o tempo da infância é o tempo de aprender a aprender, aprender fazendo e fazendo para aprender, e muito mais de aprender com as crianças.

A criança é um sujeito social histórico que está inserido em uma sociedade na qual partilha de uma determinada cultura. É profundamente marcada pelo meio social em que se desenvolve, mas também contribui com ele (S.E.B, 2006, p.25).

Os seres humanos necessitam em todas as fases de desenvolvimento de sua vida de momentos que lhes propiciem emoção, satisfação, alegria e prazer. $\mathrm{E} 0$ ato de brincar proporciona aos seres humanos de qualquer faixa etária tais satisfações. Pois para Santos (2008), "O brincar é uma característica vital do ser humano, pois se sabe que independentemente de época, cultura ou classe social todas as pessoas do mundo um dia já brincaram e as atividades realizadas ninguém esquece por mais que o tempo passe" (p.23). E para Wallon, (1975), A criança aprende muito a brincar o que aparentemente ela faz apenas para distrair-se ou gastar energia á na realidade uma importante ferramenta para o seu desenvolvimento cognitivo, emocional, social e psicológico (p.45).

Quando brinca a criança entende o mundo à sua volta e assim, trabalham aspectos como frustração, baixa estima e outros. Portanto, brincar deixa de ser apenas um ato prazeroso, para ser também, altamente benéfico para as crianças, tornando-se uma condição saudável de todo o processo evolutivo neuropsicológico. A brincadeira manifesta a forma como a criança está organizando a realidade e lidando com suas possibilidades, limitações e conflitos já que muitas vezes, ela não sabe ou não pode falar a respeito deles.

Quando brinca a criança entende o mundo à sua volta e assim, trabalham aspectos como frustração, baixa estima e outros. Portanto, brincar deixa de ser apenas um ato prazeroso, para ser também, altamente benéfico para as crianças, tornando-se uma condição saudável de todo o processo evolutivo neuropsicológico. A brincadeira manifesta a forma como a criança está organizando a realidade e lidando com suas possibilidades, limitações e conflitos já que muitas vezes, ela não sabe ou não pode falar a respeito deles.

O brinquedo estimula a curiosidade, a iniciativa e a autoconfiança; proporcionando à aprendizagem 0 desenvolvimento da linguagem, do pensamento da concentração e da atenção.

Brincando e jogando, a criança aplica seus esquemas mentais à realidade que a cerca, aprendendo-a e assimilando-a. Brincando e jogando, a criança reproduz as suas vivências, transformando o real de acordo com seus desejos e interesses. Por isso, pode-se dizer que, através do brinquedo e do jogo, a criança expressa, assimila e constrói sua realidade.

Segundo Piaget: "Os jogos não são apenas uma forma de entretenimento para gastar energias das crianças, mas meios que contribuem e enriquecem 0 desenvolvimento 
intelectual". A ideia de aplicar o lúdico à educação difundiu-se, principalmente a partir do movimento da Escola Nova. O brinquedo surge nesta perspectiva para enriquecer a atividade lúdica desenvolvendo assim o papel relevante que concernem às atividades cotidianas da criança.

A escola deve aproveitar as atividades lúdicas para aprimorar o desenvolvimento físico, mental e social da criança fazendo com que linguagem e brinquedo mostram sua origem comum em e vários aspectos e que através do símbolo lúdico corporal e concreto, pode-se orientar a criança para o mundo as palavras e chamar atenção para a possibilidade de jogo imaginário ser usado para facilitar a aquisição da linguagem, tanto oral como escrita, sendo que para isso acontecer, deve existir um paralelo entre a linguagem e a ação que envolve relação entre os dois modos de atuar, o lúdico e o linguístico.

Toda atividade que propicie prazer, entretenimento, alegria, relaxamento e diversão pode ser caracterizada como uma atividade lúdica. Conforme afirma Maluf, 2008: "atividade lúdica é toda e qualquer animação que tem como intenção causar prazer e entretenimento em quem a pratica" (p.21). Ao mesmo tempo em que tais atividades podem propiciar todos os quesitos citados promovem também para a criança aprendizagens nos mais variados aspectos e interações proporcionadas pelo lúdico evidenciam a ação, o movimento de quem a pratica, pois do contrário o que existe é passividade o que de modo algum converge para o assunto abordado.

O lúdico tem diversas interpretações de acordo com diferentes autores, mas o mais importante é que o interpretam como um importante recurso que contribui significativamente para 0 ensino e aprendizagem.

E pelo fato de a infância, o lúdico e a brincadeira estarem intrinsicamente ligados e que é algo ligado diretamente a criança devemos aproveitar esta fase para abstrair tudo o que há de positivo em prol de uma aprendizagem divertida e significativa.

\section{1.-Brincar na escola.}

O brincar na escola durante muito tempo foi desconsiderado como metodologia de ensino e o professor que utilizava desse recurso era mal visto até pelos próprios colegas e era considerado como alguém que não queria ensinar e sim só passar o tempo. Hoje se percebe que as opiniões estão mudando e que a criatividade do professor conta muito para a formação plena do aluno.

Na busca de novas metodologias de ensino que chame a atenção do aluno e que, além disso, alcance o principal objetivo da educação que é a formação plena do aluno, o professor das séries iniciais do ensino fundamental, encontra no lúdico um aliado muito forte, que sendo bem explorado será capaz de alcançar no aluno o objetivo propostos, de forma satisfatória e produtiva. Mas para conseguir alcançar tais objetivos, tem todo um processo de busca e planejamento.

Como afirma Maluf (2009), o professor deve organizar suas atividades, selecionando aquelas mais significativas para seus alunos. Em seguida deverá criar condições para que estas atividades significativas sejam realizadas. Destaca-se a importância dos alunos trabalharem na sala de aula, individualmente ou em grupos. As brincadeiras enriquecem o currículo, podendo ser propostas na própria disciplina, trabalhando assim o conteúdo de forma prática e no concreto. Cabe ao professor, em sala de aula ou fora dela, estabelecer metodologias e condições para desenvolver e facilitar este tipo de trabalho (p29). 
Na parte introdutória dos PCNs do ensino fundamental diz que: Os alunos não contam exclusivamente com o contexto escolar para construção do conhecimento sobre conteúdos considerados escolares. A mídia, a família, a igreja, os amigos, são também fontes de influência educativa que incidem sobre o processo de construção de significados desse conteúdo. Essas influências sociais normalmente somam-se ao processo de aprendizagem escolar, contribuindo para consolidá-lo; por isso é importante que a escola as considere e as integre ao trabalho. Porém, algumas vezes essa mesma influência pode apresentar obstáculo à aprendizagem escolar, ao indicar uma direção diferente, ou mesmo oposta, daquela presente no caminho escolar. É necessário que a escola considere tais direções e forneça uma interpretação dessas tais diferenças, para que a intervenção pedagógica favoreça a ultrapassagem desses obstáculos num processo articulado de interação e integração (p. 39).

\section{2.-O lúdico nas séries iniciais do ensino fundamental.}

O lúdico é importante em todas as fases de desenvolvimento da criança, pois quando participa de atividades recreativas aprende brincando, de uma forma prazerosa e significativa para a sua aprendizagem, porque a partir do momento em que ela participa ativamente de tais atividades, estará neste momento construindo seu próprio conhecimento.

A criança que brinca desenvolve de forma inconsciente sua linguagem oral, suas habilidades auditivas e sociais, seu pensamento associativo, construindo assim conceitos de relações espaciais e se aprimorando nas relações de conservação, classificação, seriação e muitos outros.

O mais interessante é que para criar um ambiente que possa atrair a curiosidade da criança, a escola não precisa disponibilizar de uma quantidade enorme de caríssimos brinquedos eletrônicos ou jogos ditos educativos, não que estes não sejam importantes, porém mais do que ter acesso a jogos modernos e de custo elevado é necessário ter uma equipe de educadores que saibam trabalhar de forma criativa e reflexiva, e que saiba despertar 0 interesse dos alunos para o novo. Sendo que esse novo possa partir de algo como simples objetos naturais e que se transforme dando-os a oportunidade da descoberta e exploração de sua imaginação.

Portanto o uso de jogos, brincadeiras e outras atividades que envolvem a ludicidade podem mediar aprendizagens nesta fase de desenvolvimento, onde aprender a colocar-se no lugar do outro e desenvolver a capacidade de trocar experiências e o conceito de autoridade são tarefas importantíssimas, neste novo século e devem fazer parte de todos os currículos escolares e da vida, de todos os educandos (Maluf, 2008, p.26).

Para Rapoport (2009): 0 ingresso no ensino fundamental é mais um momento de transição na vida da criança, trazendo-lhe muitas novidades e desafios, às vezes vividos com plena alegria e tranquilidade, outras com insegurança, ansiedade ou medo. Dessa forma, este é um evento que requer adaptação da criança e de todos os envolvidos no processo. Considerandose a entrada com sei anos de idade, as peculiaridades da faixa etária e a recente implantação do ensino fundamental de nove anos nas redes de ensino públicas e privadas no Brasil, a adaptação está envolvendo um universo maior, pois se constitui em fato novo para todos. (p.23). 
A criança de seis anos possui características e necessidades específicas, as quais precisam ser consideradas nos processos e práticas educativas. Diante do reconhecimento das características das crianças de seis anos, as orientações do MEC salientam também sua preocupação com o processo de ingresso e adaptação. "É necessário que o sistema escolar esteja atento às situações envolvidas no ingresso da criança no ensino fundamental, seja ela oriunda diretamente da família, seja da pré-escola, a fim de manter os laços sociais e afetivos e as condições de aprendizagem.

Quando as crianças ingressam nas escolas entram com uma expectativa muito grande sobre o que vão encontrar, por isso a escola deve criar um ambiente atrativo e acolhedor com atividades que chamem a atenção de sua clientela, devendo tomar cuidado para não as frustrar, pois irão frequentar este espaço institucional por muitos anos de sua vida. Nesse momento alguns questionamentos são colocados novamente referindo a importância do processo de adaptação.

A professora também é uma figura de referência nova com a qual a criança deve estabelecer uma relação diferenciada daquela que está acostumada nos contatos sociais não formais. Além dessas questões, o Próprio aspecto cognitivo vem, muitas vezes, pouco estimulado, tendo a criança que aprender a manusear novos materiais (tesoura, cola, lápis, folha, etc.), aprender a se organizar e começar a conhecer, a ter contato e manusear conceitos científicos (Rapoport, 2009, P.25).

Como percebemos a criança ao ingressar neste novo panorama de sua vida se depara com algumas situações novas e diferentes do que tem vivenciado e o professor deve facilitar a entrada nesse novo universo. Com o lúdico atende-se uma necessidade básica da criança, por isso a rotina da escola deve prevê algum tempo para estas atividades, e esta perspectiva não engloba apenas o uso de jogos e brincadeiras como recurso de ensino de conteúdo, não que não sejam importantes, mas o sentido que nos referimos exatamente, compreende a brincadeira como fruto da ação livre e voluntária, com a conotação de dar prazer aos envolvidos e deixá-los "à vontade" para produzir de forma criativa.

\section{3.-A ludicidade e a prática educativa.}

Os jogos e brincadeiras têm capacidade de despertar interesse pela aprendizagem nas aulas, pois tem caráter interativo e interdisciplinar além de dar a oportunidade de monitoração e correção de condutas sociais.

Assim, entendemos que a brincadeira é a principal atividade da criança que se constrói numa ocupação comprometida que o adulto na maioria das vezes não valoriza opondo-se a elas, acabam substituindo-a por outra tarefa que julga importante.

Por esse motivo é fundamental que esses recursos sejam utilizados pela escola, no entanto, é preciso considerar os aspectos diferentes onde pode - se trabalhar o lúdico. O lúdico ajuda a criança no seu desenvolvimento físico, afetivo, intelectual e social, pois, através das atividades lúdicas, a criança forma conceitos, relaciona ideias, estabelece relações lógicas, desenvolve a expressão corporal, reforça habilidades sociais, reduz a agressividade, integrase na sociedade e constrói seu próprio conhecimento.

A atividade lúdica é essencialmente para o desenvolvimento da criatividade e potencialidade da criança ao mesmo tempo que propicia o prazer, tanto que esta ideia está presente na definição de muitos teóricos importantes da educação, embora alguns defendem que o prazer nem sempre está presente tendo em vista que pode causar naqueles que praticam algum 
jogo com regras com finalidade competitiva algum tipo de frustração. Com este pressuposto torna-se interessante destacar que é importante a condução das referidas atividades de forma harmoniosa.

A atividade lúdica é a ação que pode propiciar a plenitude da experiência, por isso proporciona prazer ao ser humano, seja como exercício, como jogo simbólico ou como jogo de regras. Ele afirma, ainda que uma atividade lúdica pode não ser divertida. (Luckesi apud Maluf,2008, P.22).

Acreditamos nesta ferramenta de trabalho, pois o uso do lúdico é o brincar aprendendo e também uma ferramenta didática para o processo de ensino e aprendizagem do aluno. Quando não se conhece o lúdico pode até parecer que se está perdendo tempo, mas o lúdico com crianças tem dado certo. Estudos e pesquisas têm comprovado a importância das atividades lúdicas no desenvolvimento das potencialidades humanas das crianças, proporcionando condições adequadas ao seu desenvolvimento físico, motor, emocional, cognitivo e social (Maluf, 2008, p.11).

Há muito tempo que o lúdico foi implantado nas escolas, porém com objetivo de contribuir com 0 ensino e aprendizagem da criança, que nada mais justo por serem crianças. Temos que valorizar o lúdico muito mais em sala de aula, devemos valorizá-lo como instrumento de ensino e ferramenta pedagógica, munindo os profissionais epistemologicamente para que possam interagir no processo, assim como usá-lo para que possa ajudá-lo na construção dos conhecimentos. Para que esta construção venha dar certo e o objetivo alcançado é necessário que o professor desenvolva com os alunos um processo de ensino e aprendizagem criativo e desafiador.

O favorecimento do Progresso da criança do ensino fundamental conforme especificado na tabela a seguir:

O progresso do aluno é detectado através daquilo que é observado por meio das habilidades e capacidades que o mesmo apresenta em desenvolver determinadas atividades.

Para isso, o trabalho escolar deve ser pensado no sentido do desenvolvimento de capacidades, permitindo que as atividades desenvolvidas através do lúdico possam ser aplicadas a todas as disciplinas e que estejam integradas. Pois a partir de algumas brincadeiras, jogos e dinâmicas o professor poderá trabalhar vários aspectos como concentração, responsabilidade, noções de lateralidade, espaço e tempo, memorização, interação, integração entre outros aspectos de relevância que precisam ser trabalhados com alunos da educação infantil.

\section{3.-Metodologia.}

A pesquisa foi realizada no ano de 2011, no município de Alto Alegre, uma pequena cidade do Estado de Roraima, situada no extremo norte do Brasil. 0 município possui atualmente, com base no último Censo, 16.200 habitantes, onde apenas 7.000 hab. vivem na zona urbana, sede do município. Embora o município seja pequeno e tenha uma população considerada pequena em relação as grandes cidades.

A investigação ocorreu nos meses de setembro, outubro e novembro de 2011, na Escola Municipal Professora Edneide Sales Campêlo que está localizada no Centro de Alto Alegre, na avenida $1^{\circ}$ de julho $n^{\circ} 979$, é uma escola de modelo padrão, construída pelo governo do estado de Roraima. 
Esta é uma pesquisa de modelo não-experimental, pois o pesquisador em nenhum momento irá manipular nenhuma das variáveis. É uma pesquisa que ocorrerá através do modelo descritivo, pois tem como objetivo além coletar dados do objeto em estudo fazer uma análise sobre como acontece a inter-relação entre as variáveis, bem como descrever sobre todos os dados coletados a fim de alcançar uma melhor visão e compreensão do objeto da pesquisa. Para tanto, foi utilizado um paradigma interpretativo com enfoque qualitativo, tendo como fontes de coleta de dados entrevistas semiestruturadas e que facilitará o entendimento sobre o tema.

A pesquisa aconteceu através da técnica de entrevistas individual semiestruturadas com perguntas abertas e fechadas aplicada aos 14(catorze) professores do $1^{\circ}$ ano do ensino fundamental da Escola Municipal Professora Edneide Sales Campêlo. "As entrevistas semiestruturadas tem a liberdade de introduzir mais questões para a precisão de conceitos ou obter maior informação sobre os temas desejados" (Sampieri Et. al., 2006, p.381).

\section{4.-Discussões dos resultados.}

A entrevista feita aos professores possibilitou o acesso a muitas informações e reflexões, o que tornou possível fazer a análise e interpretação dos dados. Os dados coletados permitiram uma melhor visão sobre a importância do lúdico no processo de ensino e aprendizagem da Escola Municipal Professora Edneide Sales Campelo. Segue abaixo o objetivo da pesquisa.

4.1.-Verificar se as atividades lúdicas como recurso pedagógico podem desenvolver práticas mais atrativas segundo a percepção dos professores.

As atividades lúdicas (jogos, histórias, músicas, brincadeiras, (...), quando utilizadas como recurso pedagógico, são ingredientes indispensáveis para a interação entre as pessoas, dentro do convívio escolar. Entretanto, estas atividades precisam estar bem planejadas para poder alcançar práticas mais atrativas, deve ser desenvolvida de acordo com as especificidades de cada educando, possibilitando a construção da afetividade, prazer, autoconhecimento, cooperação, autonomia, imaginação e criatividade, permitindo assim, que a criança construa e partilhe o seu conhecimento com os outros, com alegria de querer aprender e crescer intelectualmente cada vez mais.

4.2.-Categoria: Professores do $1^{\circ}$ ano do ensino fundamental da Escola Municipal Professora Edneide Sales Campelo.

As questões da investigação proposta na realização da entrevista aos professores da Escola Municipal Professora Edneide Sales Campelo foram estruturadas com a intenção de responder com maior clareza os objetivos da referida pesquisa. Para iniciar a entrevista é muito importante ter a informação se os professores conhecem sobre o significado termo lúdico e para melhor esclarecimento foi elaborada a $1^{\text {a }}$ questão da entrevista: 0 que você considera por lúdico? A resposta da referida pergunta está ilustrada na tabela abaixo:

Quadro 2.-Resultado da $1^{\text {a }}$ (primeira) questão da entrevista realizada aos professores do $1^{0}$ ano do ensino fundamental da Escola Municipal Professora Edneide Sales Campelo. 


\begin{tabular}{|l|l|}
\hline & \multicolumn{1}{c}{ O que você considera por lúdico? } \\
\hline P1,P3 e & $\begin{array}{l}\text { É uma maneira de atrair o aluno para a aprendizagem, através da diversão, } \\
\text { socialização e interação. }\end{array}$ \\
\hline P5 & $\begin{array}{l}\text { É uma maneira prazerosa de ensinar e aprender utilizando material concreto } \\
\text { onde o aluno possa manuseá-lo. }\end{array}$ \\
\hline P2 & $\begin{array}{l}\text { Um recurso inovador que vem contribuindo de forma significativa e proveitosa } \\
\text { para o ensino-aprendizagem. }\end{array}$ \\
\hline P4 & $\begin{array}{l}\text { São atividades que focalizam o brinquedo, brincadeira, os jogos, e } \\
\text { divertimento que possuem caráter de movimento, diversão, recreação desafio } \\
\text { e entretenimento. }\end{array}$ \\
\hline P6, P13 & $\begin{array}{l}\text { É a maneira por meio da motivação que desperta o gosto pela leitura em } \\
\text { qualquer disciplina onde o alunado aprenderá a ler brincando. }\end{array}$ \\
\hline P7 e & $\begin{array}{l}\text { É uma forma prazerosa de se ensinar e aprender, pois o brincar tem } \\
\text { fundamental importância no desenvolvimento infantil, consolidando diferentes } \\
\text { P14 }\end{array}$ \\
\hline P8 e Pacterísticas.
\end{tabular}

Fonte: Entrevista feita aos Professores do $1^{\circ}$ ano do ensino fundamental da Escola Municipal Professora Edneide Sales Campelo, Setembro de 2011.

Pelas respostas dadas pelos professores na tabela acima, podemos perceber que entendem que o lúdico é o brincar, brinquedo, brincadeira, jogos que propiciam as crianças a descontração, divertimento, recreação, desafio, entretenimento, socialização e interação. Descrevem o termo lúdico ainda como um recurso inovador que vem contribuindo de forma significativa e proveitosa para o ensino-aprendizagem.

Evidencia-se nas respostas dos professores que o termo lúdico é um tema conhecido na Escola Municipal Professora Edneide Sales Campelo. Esse conhecimento torna-se relevante, principalmente quando utilizado na prática, como uma ferramenta para trabalhar currículo escolar, tendo em vista que é um recurso indispensável para a inserção dos alunos no âmbito educacional, por se tratar de algo que atrai sua atenção, que propicia prazer, entretenimento, alegria, relaxamento, diversão, interação e aprendizagem.

Segundo o Dicionário Aurélio Buarque de Holanda Ferreira da Língua Portuguesa o termo lúdico possui o seguinte significado: "Relativo a jogos, brinquedos e divertimentos". (Ferreira, 2005, p.553). Santos, 1997 afirma que: "A palavra lúdica vem do latim ludus e significa brincar. Nesse brincar estão incluídos os jogos, brinquedos e divertimentos e é relativa também a conduta daquele que joga, que brinca e que se diverte (p.9). 
Maluf (2008), enfatiza que: "Atividade lúdica é toda e qualquer animação que tem como intenção causar prazer e entretenimento em quem a pratica. São lúdicas as atividades que propiciam experiência completa do momento, associando o ato, o pensamento e o sentimento. A atividade lúdica pode ser uma brincadeira, um jogo ou qualquer outra atividade que vise proporcionar interação. Porém, mais importante do que o tipo de atividade lúdica é a forma como ela é dirigida e vivenciada, e o porquê de sua realização"( Maluf, 2008, p.21).

Com a intenção de analisar como acontece o ensino com a utilização do lúdico na Escola Municipal Professora Edneide Sales Campêlo, perguntou-se aos professores do $1^{\circ}$ ano ensino fundamental da referida escola na $2^{\mathrm{a}}$ questão da entrevista: Como você considera o ensino com a utilização do lúdico? A pergunta teve como resposta os posicionamentos que estão descritos na tabela abaixo:

Quadro 3.-Resultado da $2^{\mathrm{a}}$ (segunda) questão da entrevista realizada aos professores do $1^{0}$ ano do ensino fundamental da Escola Municipal Professora Edneide Sales Campêlo.

\section{Pergunta}

\section{Como você considera o ensino com a utilização do lúdico?}

\section{Resposta dos Professores}

P1, P2, É de fundamental importância para o desenvolvimento cognitivo do aluno e as $\mathrm{P} 10 \mathrm{e}$ atividades devem ser elaboradas conforme a faixa etária da criança, tornando-

P11 se, relevante no desenvolvimento de qualquer processo educativo.

P3 e P6 O ensino planejado torna-se mais produtivo e atraente, favorecendo a interação, o despertar da curiosidade e interesse do aluno, privilegiando o ensino e aprendizagem.

P4 e P5 O ensino com a utilização do lúdico torna-se atrativo, divertido, prazeroso e dinâmico, um método inovador diferente da rotina, vindo privilegiar o ensino $\mathrm{e}$ aprendizagem.

P7 e P8 Uma maneira mais fácil de se aprender brincando usando sempre que possível material concreto, como por exemplo: jogos pedagógicos.

P9 e Uma excelente metodologia para se alcançar objetivos no ensino

P13 aprendizagem, pois prende a atenção do aluno e 0 ensino se torna mais prazeroso e produtivo.

P12 e A utilização do lúdico como promoção do conhecimento é muito proveitoso P14 porque deixa 0 aluno descontraído, a vontade pronta para participar ativamente do processo ensino e aprendizagem. É eficaz e menos estressante tanto para 0 aluno quanto para o professor.

Fonte: Entrevista realizada aos Professores do $1^{\circ}$ ano do ensino fundamental da Escola Municipal Professora Edneide Sales Campêlo, setembro de 2011.

Visualiza-se nas respostas dos professores que o ensino com a utilização do lúdico é um ponto positivo, principalmente quando este tem a intenção de aprimoramento da aprendizagem, favorecendo-o no seu desenvolvimento cognitivo, tornando o ensinar e 0 aprender mais atrativo e proveitoso. Além de propiciar um planejamento de qualidade e uma metodologia mais eficaz para a construção da aprendizagem, fazendo com que o educador alcance com sucesso a concretização dos objetivos propostos. 
Neste sentido, Santos (2008) afirma que: A educação pela via da ludicidade propõe-se a uma nova postura existencial cujo paradigma é um novo sistema de aprender brincando, inspirado numa concepção de educação para além da instrução. Para que isso aconteça é preciso que os profissionais da educação reconheçam o real significado do lúdico para aplicá-lo adequadamente, estabelecendo a relação entre o brincar e o aprender (p.24).

Nesta perspectiva, a utilização do lúdico com ferramenta pedagógica aplicado de forma correta, respeitando a faixa etária do aluno, seu desenvolvimento cognitivo, sendo bem planejado e direcionado, torna o ensino mais atrativo, prazeroso, divertido, produtivo e eficaz e capaz de alcançar todos os objetivos propostos.

Com o objetivo de analisar na escola Municipal Professora Edneide Sales Campêlo se as atividades lúdicas como recurso pedagógico desenvolvem práticas pedagógicas mais atrativas para alunos do $1^{\circ}$ ano do ensino fundamental, elaborou-se a $3^{\text {a }}$ (terceira) questão da entrevista: As atividades lúdicas como recurso pedagógico podem desenvolver práticas mais atrativas para alunos do $1^{\circ}$ ano do ensino fundamental? $E$ obteve-se as respostas dos professores que foram colocados no quadro abaixo:

Quadro 4.-Resultado da $3^{\mathrm{a}}$.(terceira) questão da entrevista realizada aos professores do $1^{\circ}$ ano do ensino fundamental da Escola Municipal Professora Edneide Sales Campêlo.

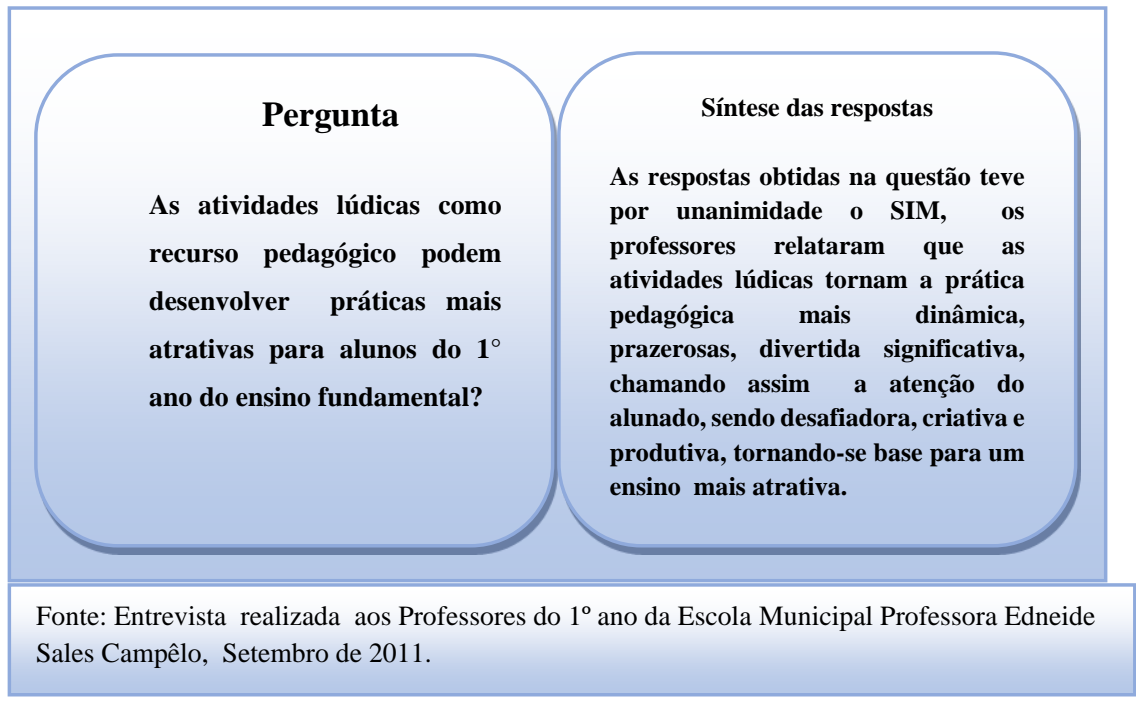

Ao brincar a criança além de divertir-se ela também aprende, desenvolve novas habilidades, aprende novos conceitos, cria novas coisas, em fim desenvolve a autonomia fundamental para sua formação e necessária a todas as etapas de sua vida. Como afirma Maluf (2009): "Toda criança que brinca vive uma infância feliz, além de tornar-se um adulto muito mais equilibrado física e emocionalmente, conseguirá superar com mais facilidade, problemas que possam surgir no seu dia-a-dia" (p.21). A criança sente-se ao mesmo tempo, prestigiada e desafiada quando o parceiro da brincadeira é um adulto. Este por sua vez, pode levar a criança a fazer descobertas e a viver experiências que tornam o brincar mais estimulante $\mathrm{e}$ mais rico em aprendizado (Maluf, 2009, p. 30). 
Segundo Maluf (2009): A criança é curiosa e imaginativa, está sempre experimentando o mundo e precisa explorar todas as suas possibilidades. Ela adquire experiência brincando. Participar de brincadeiras é uma excelente oportunidade para que a criança viva experiências que irão ajudá-la a amadurecer emocionalmente e aprender uma forma de convivência mais rica (p21).

Por meio das respostas dadas pelos professores, na questão três, podemos perceber que as atividades lúdicas, quando utilizadas como recursos pedagógicos tornam-se instrumentos essenciais para a prática pedagógica, fazendo com que as aulas sejam mais atrativas e incentivadoras, levando 0 alunado a ter um maior interesse em aprender e partilhar suas habilidades para com os outros colegas. Sendo isso, de suma importância para 0 desenvolvimento educativo dentro de uma instituição escolar.

Com o intuito de esclarecer com resposta dos professores da Escola Municipal Professora Edneide Sales Campêlo, se com utilização da brincadeira como recurso pedagógico propiciase momentos de descontração e aprendizagem, foi criada a $4^{a}$ (quarta) pergunta da entrevista: A brincadeira como atividade pedagógica promove momentos de descontração e aprendizagem? Nesta questão obteve-se a resposta que será ilustrada no esquema abaixo:

Quadro 5.-Resultado da $4^{a}$. (quarta) questão da entrevista realizada aos professores do $1^{\circ}$ ano do ensino fundamental da Escola Municipal Professora Edneide Sales Campêlo.

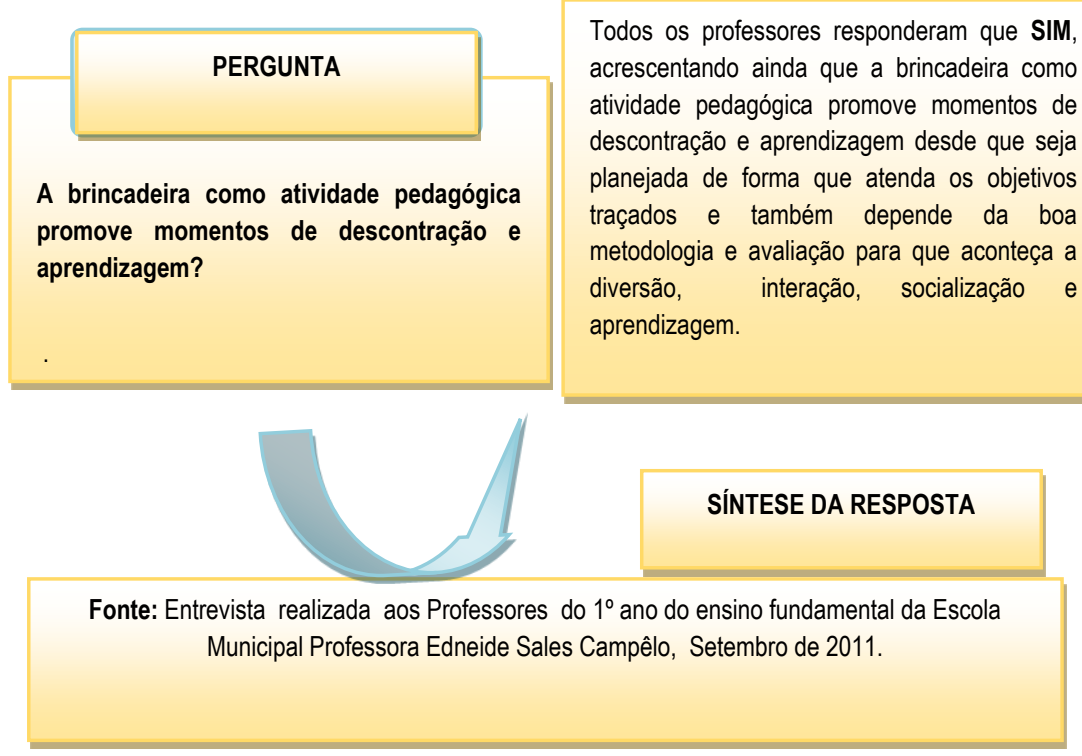

Acredito que através do brincar a criança prepara-se para aprender. Brincando ela aprende novos conceitos, adquire novas informações e tem um crescimento saldável. (...) Quando brincamos exercitamos nossas potencialidades, provocamos o funcionamento do pensamento, adquirimos conhecimento sem estresse ou medo, desenvolvemos a sociabilidade, cultivamos a sensibilidade, nos desenvolvemos intelectualmente, socialmente e emocionalmente. Assim também ocorre com as crianças: elas mostram que são dotadas de criatividade, imaginação e inteligência (Maluf, 2009, p.20 e 21). 
Aqui é visível, quando todos os professores concordam que as brincadeiras bem planejadas e organizadas acabam ajudando na aprendizagem, desde que seja planejada com objetividade e que a metodologia e avaliação estejam adequadas aos objetivos traçados.

Acredita-se que quando se planeja com o lúdico de forma adequada e com objetividade é possível se ter sucesso na aprendizagem do educando, por saber que a criança que brinca com seriedade aprende mais e com mais facilidade. As atividades lúdicas têm como característica principal a descontração e entretenimento e como ferramenta pedagógica é um rico recurso por que alia o prazer de brincar ao processo de aprendizagem. Nada melhor do que aprender brincando e para que o processo de aprendizagem seja completo deve ser planejado, executado e avaliado. Com o objetivo de descrever o lúdico e as contribuições para o ensino e aprendizagem para os alunos do $1^{\circ}$ ano do ensino fundamental, perguntou-se para os professores, na $5^{\mathrm{a}}$ questão: 0 lúdico como recurso pedagógico fortalece o ensino e a aprendizagem de alunos do $1^{\circ}$ ano do ensino fundamental? 0 esquema abaixo demonstra 0 resultado obtido na referida questão.

Quadro 6.-Resultado da $5^{a}$. (quinta) questão da entrevista realizada aos professores do $1^{0}$ ano do ensino fundamental da Escola Municipal Professora Edneide Sales Campêlo.

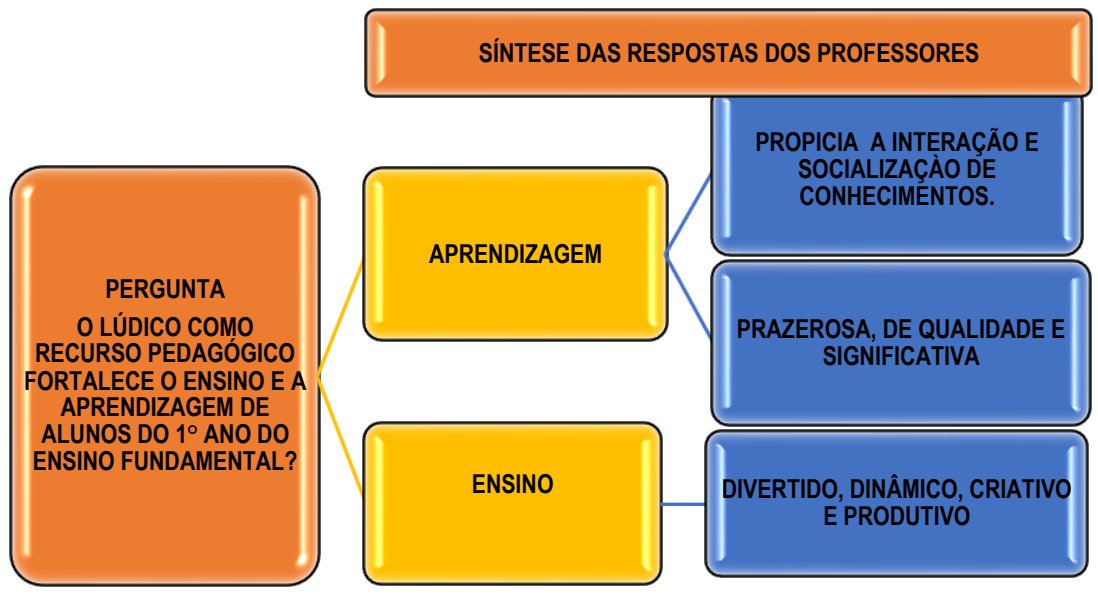

Fonte: Entrevista realizada aos Professores do $1^{\circ}$ ano do ensino fundamental da Escola Municipal Professora Edneide Sales Campêlo, Setembro de 2011.

De acordo com que foi analisado no esquema acima, é fácil verificar que para os educadores da Escola Municipal Professora Edneide Sales Campelo, o lúdico quando bem trabalhado vem enriquecer o ensino, propiciando a interação e socialização de conhecimento entre as crianças no ambiente escolar, transformando o ensinar em algo divertido, dinâmico, criativo e produtivo. Levando, portanto, a criança alcançar de forma prazerosa uma aprendizagem de qualidade e significativa para o seu a crescer como pessoa sociável. As atividades lúdicas são instrumentos pedagógicos altamente importantes, mais do que entretenimento, são um 
auxílio indispensável para o processo de ensino-aprendizagem, que propicia a obtenção de informações em perspectivas e dimensões que perpassam o desenvolvimento do educando. A ludicidade é uma tática insubstituível para ser empregada como estímulo no aprimoramento do conhecimento e no progresso das diferentes habilidades (Maluf, 2008, p.42). O lúdico como recurso pedagógico é uma ferramenta que supera as expectativas de um instrumento de ensino, por se tratar de uma atividade dinâmica, divertida e atrativa para a criança, é um meio eficaz que fortalece 0 ensino e estimula a aprendizagem. No ato em que pratica a brincadeira, a criança está fazendo algo que além de lhe proporcionar entretenimento e prazer está promovendo de forma prática o uso da imaginação de forma criativa, propiciando a construção de conhecimentos, habilidades e competências, interação, socialização e desenvolvendo 0 lado afetivo e emocional. Todos os quesitos citados só poderiam ser desenvolvidos através de uma atividade prática que não pode ser passado de uma pessoa para outra, são conhecimentos que somente com a prática podem ser adquiridos. Com a intenção de obter informações para uma análise mais detalhada sobre os alunos quando colocados em um ambiente lúdico se produzem com mais facilidade, foi perguntado aos professores do $1^{\circ}$ ano do Ensino Fundamental da Escola Municipal Professora Edneide Sales Campêlo, na $6^{\mathrm{a}}$ questão, da seguinte forma: $O$ aluno do $1^{\circ}$ ano do ensino fundamental quando colocado em um ambiente lúdico o aluno produz com mais facilidade? De acordo com a resposta da pergunta proposta obteve-se o seguinte resultado:

Quadro 7.-Resultado da $6^{\mathrm{a}}$.(sexta) questão da entrevista realizada aos professores do $1^{0}$ ano do ensino fundamental da Escola Municipal Professora Edneide Sales Campêlo.

\begin{tabular}{|c|c|c|}
\hline $\mathbf{N}^{0} \mathrm{DA}$ & PERGUNTA & SÍNTESE DA RESPOSTA \\
\hline 06 & $\begin{array}{l}0 \text { aluno do } 1^{\circ} \text { ano do } \\
\text { ensino fundamental } \\
\text { quando colocado em } \\
\text { um ambiente lúdico } 0\end{array}$ & $\begin{array}{l}\text { Todos concordam que os alunos produzem com } \\
\text { mais facilidade e afirmam que este é um ambiente } \\
\text { amplo, o desafiador, atrativo, acolhedor que } \\
\text { desperta a curiosidade, a imaginação e sensação } \\
\text { de prazer. Além disso, desenvolve valores morais, }\end{array}$ \\
\hline & $\begin{array}{l}\text { aluno produz com } \\
\text { mais facilidade? }\end{array}$ & $\begin{array}{l}\text { intelectuais e se oportunizam momentos de } \\
\text { expressão, criação, interação e troca de } \\
\text { conhecimento, é um ambiente que trabalha com o } \\
\text { real, concreto, o que promove momentos de } \\
\text { contextualização estimulando a inteligência e que } \\
\text { torna os resultados eficazes. }\end{array}$ \\
\hline
\end{tabular}

Fonte: Entrevista realizada aos Professores do $1^{\circ}$ ano do ensino fundamental da Escola Municipal Professora Edneide Sales Campêlo

O prazer está presente nas atividades lúdicas. A criança fica absorvida de forma integral. Criase um clima de entusiasmos. Podemos ressaltar que grandes educadores do passado já reconheciam a importância das atividades lúdicas no processo de ensino- aprendizagem. A criança se expressa, assimila conhecimentos e constrói a sua realidade quando está em alguma atividade lúdica. Ela também espelha a sua experiência, modificando a realidade de acordo com os seus gostos e interesses. (Maluf, 2008, P.23).

De acordo com que foi analisado no esquema acima, é fácil verificar que para os educadores do $1^{\circ}$ ano do ensino fundamental da Escola Municipal Professora Edneide Sales Campelo, 
um ambiente lúdico é fundamental para facilitar a aprendizagem, propiciando a interação e socialização de conhecimento entre as crianças no ambiente escolar, transformando o ensinar em algo divertido, dinâmico, criativo e produtivo. Levando, portanto, a criança alcançar de forma prazerosa uma aprendizagem de qualidade e significativa para o seu a crescer como pessoa sociável.

\section{5.-Conclusão.}

Diante do que foi exposto, podemos perceber que que as atividades lúdicas quando utilizadas como recurso pedagógico, são ingredientes indispensáveis para a interação entre as pessoas, dentro do convívio escolar. Entretanto, estas atividades precisam estar bem planejadas para poder alcançar práticas mais atrativas, deve ser desenvolvida de acordo com as especificidades de cada educando e com a faixa de idade, pois para ser interessante deve estar adequada ao aluno, possibilitando a construção da afetividade, prazer, autoconhecimento, cooperação, autonomia, imaginação e criatividade, permitindo assim, que a criança construa e partilhe o seu conhecimento com os outros, com alegria e gosto de querer aprender e crescer intelectualmente cada vez mais. Em fim as atividades lúdicas tornam a prática pedagógica mais dinâmica, prazerosas, divertida significativa, chamando assim a atenção do alunado, sendo desafiadora, criativa e produtiva, tornando-se base para um ensino mais atrativa.

\section{6.-Referências bibliográficas.}

Ferreira, A.B.H. (2005). Dicionário Aurélio Buarque de Holanda Ferreira da Língua Portuguesa. São Paulo: Positivo.

Luckesi, C. (1998). O papel da didática na formação do educador. In: Candau, V. A vida em questão. Petrópolis: Vozes.

Maluf, A.C.M. (2008). Atividades lúdicas para a educação infantil: conceitos, orientações e práticas. Petrópolis: Vozes.

Maluf, A.C.M. (2009). Brincar: Prazer e aprendizado. Petrópolis: Vozes.

Rapoport, A., Sarmento, D.F., Norberng, M., Pacheco, S.M.(Orgs). (2009). As crianças de seis anos no ensino fundamental. Porto Alegre: Mediação.

S.E.B. (2006). Parâmetros Curriculares Nacionais da Educação Infantil. Brasília: MEC.

Sampieri, R.H., Collado, C.F., Lucio. P.B. (2006). Metodologia de la Investigación. México: McGrawHill.

Santos, S.M.P. (2008). Educação, arte e jogo. Petrópolis: Vozes.

Wallon, H. (1975). Psicologia e educação da infância. Lisboa: Estampa. 